\title{
Herkansing voor infinitesimalen?
}

\author{
Sylvia Wenmackers, KU Leuven \\ Verschenen in: Algemeen Nederlands Tijdschrift voor Wijsbegeerte 110 (2018) pp. 491-510.
}

\begin{abstract}
Samenvatting Dit artikel belicht het verband tussen de zenonische magnitudeparadox en waarschijnlijkheid bij oneindige uitkomstenruimten. Twee belangrijke premissen in het zenonische argument zijn: het archimedische axioma, dat infinitesimale magnitudes verwerpt, en perfecte additiviteit. De standaard kansrekening gebruikt reële getallen die voldoen aan het archimedische axioma, maar verwerpt perfecte additiviteit. De sommeerbaarheidsvereiste voor reëelwaardige waarschijnlijkheden is namelijk beperkt tot aftelbaar oneindige collecties van elkaar uitsluitende gebeurtenissen. Een gevolg hiervan is dat er geen standaard kansfunctie bestaat die een eerlijke loterij op de natuurlijke getallen beschrijft. Als we het archimedische axioma verwerpen, en dus infinitesimale waarschijnlijkheden toestaan, kunnen we perfecte additiviteit behouden en een eerlijke, aftelbaar oneindige loterij beschrijven. Dit artikel geeft een historisch overzicht om te begrijpen hoe de eerste optie de huidige standaard is geworden, terwijl de tweede 'niet-standaard' blijft.
\end{abstract}

\section{A New Chance for Infinitesimals?}

Abstract This article discusses the connection between the Zenonian paradox of magnitude and probability on infinite sample spaces. Two important premises in the Zenonian argument are: the Archimedean axiom, which excludes infinitesimal magnitudes, and perfect additivity. Standard probability theory uses real numbers that satisfy the Archimedean axiom, but it rejects perfect additivity. The additivity requirement for real-valued probabilities is limited to countably infinite collections of mutually incompatible events. $A$ consequence of this is that there exists no standard probability function that describes a fair lottery on the natural numbers. If we reject the Archimedean axiom, allowing infinitesimal probability values, we can retain perfect additivity and describe a fair, countable infinite lottery. The article gives a historical overview to understand how the first option has become the current standard, whereas the latter remains 'nonstandard'.

Keywords: history and philosophy of mathematics, infinitesimals, infinity, probability theory

'Nicht mühelos siegt der Glauben an das Unendlichkleine.' - Paul du Bois-Reymond (1882: 73)

Infinitesimale waarschijnlijkheden drukken de objectieve kans of de rationele graad van overtuiging uit van een uitkomst die tegelijkertijd mogelijk is en uiterst onwaarschijnlijk. Hoewel het intuïtief duidelijk is wat we ermee bedoelen, maakt de huidige standaardtheorie voor kansrekening geen gebruik van dit begrip. Dat roept de vraag op of er een alternatieve kanstheorie mogelijk is op basis van infinitesimalen.

In dit artikel licht ik toe hoe infinitesimalen in de loop van de wiskundegeschiedenis keer op keer op een zijspoor beland zijn, waardoor ook infinitesimale waarschijnlijkheden hun start hebben gemist. In de jaren 1960 is er echter een belangrijke ontwikkeling geweest, die het mogelijk zou kunnen maken dat ze alsnog ingeburgerd raken.

Het artikel is als volgt gestructureerd. In sectie 1 licht ik toe hoe dit onderwerp op mijn eigen pad is gekomen. Sectie 2 geeft een selectief historisch overzicht van het concept infinitesimalen 
in de wiskunde. Sectie 3 bespreekt waarom infinitesimalen niet voorkomen in de standaard kansrekening en welke recente alternatieven er zijn. Sectie 4 biedt enkele slotbeschouwingen.

\section{Het begon met een voetnoot}

Voor mij begon het klein: ik werkte als postdoctoraal onderzoeker in de fysica en besloot toe te geven aan mijn aanhoudende nieuwsgierigheid naar grondslagenonderzoek. In Gent werd er een congres gehouden over inductie: ik nam vakantie om dit bij te wonen en hoorde er John Norton een lezing geven. Achteraf las ik zijn artikel over het onderwerp en daar stond - in een voetnoot - een opmerking die volgens mij niet juist kon zijn. Norton (2013: 10) schreef dat er geen kansverdeling bestaat die aan alle natuurlijke getallen dezelfde kans toekent. Dat geloofde ik niet.

Bij navraag bleek Nortons voetnoot correct: de standaard kansrekening heeft inderdaad geen kansfunctie die overeenkomt met wat we een eerlijke loterij op de natuurlijke getallen kunnen noemen. De voetnoot van Norton beargumenteerde het als volgt: we moeten aan elk van de aftelbaar oneindige mogelijkheden dezelfde kans toekennen, dus kans nul, maar dan sommeren de kansen niet tot één (en een kansfunctie moet genormeerd zijn). Het was die snelle 'dus kans nul' waar ik raar van opkeek. Als fysicus was ik namelijk opgeleid met een intuïtief begrip infinitesimalen: informeel beschouwen we de snelheid van een deeltje bijvoorbeeld als de infinitesimale verplaatsing gedeeld door de infinitesimale tijdsduur waarin die verplaatsing gebeurt. Mij leek het vanzelfsprekend dat de kans op elke specifieke uitkomst van een oneindige loterij een infinitesimaal was, zodat je de infinitesimale kansen van alle loten zou kunnen sommeren tot kans één.

Wiskundigen schudden echter hun hoofd bij deze informele beschrijving. Zij definiëren een snelheid als de limiet van eindige breuken - zoals we zien in de volgende sectie. En ervaren filosofen zien de rode vlaggen 'intuïtief' en 'vanzelfsprekend' al van ver wapperen.

Maar ik had beginnersgeluk. In de bibliotheek trof ik het werk van Bruno de Finetti aan, waarin hij mijn intuïtie over de sommeerbaarheid van kansen glashelder beschreef als perfecte additiviteit, die hij echter meteen terzijde schoof als iets dat wiskundig onhaalbaar is (de Finetti, 1972: 92). Het was mij toen nog niet duidelijk waarom. Ik raakte zo verdiept in dit probleem, dat ik besloot om mijn labojas af te leggen en een tweede doctoraat te schrijven over dit onderwerp (Wenmackers, 2011).

In dit artikel geef ik de systematische inleiding waar het mij toen aan ontbrak. Want natuurlijk was het niet begonnen met die voetnoot. De huidige status quo vindt zijn oorsprong millennia eerder.

\section{Geschiedenis van het concept infinitesimaal}

Infinitesimalen worden ook wel oneindig kleine grootheden genoemd. Ze drukken een hoeveelheid uit die verschilt van nul, maar die zo klein is dat het niet uit te drukken is met een positief (reëel) getal. Om onduidelijkheid te vermijden begin ik met een formele definitie. De rest van deze sectie geeft een selectie van de Westerse wiskundegeschiedenis tot aan de eerste axiomatisatie van de kansrekening in 1933.

\section{$2.1 \quad$ Infinitesimalen en niet-archimedische velden}

We zullen in dit artikel de volgende definitie gebruiken, gebaseerd op een axioma dat voorkomt bij Eudoxus, Euclides en Archimedes (die dit soort grootheden uitsloten):

Een getal $x \neq 0$ is infinitesimaal enkel en alleen indien de absolute waarde van $x$ kleiner is dan $1 / n$ voor alle natuurlijke getallen $n$. 
De reële getallen vormen samen met de vier hoofdbewerkingen (optelling, aftrekking, vermenigvuldiging en deling) een algebraïsche structuur die een 'veld' genoemd wordt. In het reële veld is er geen enkel van nul verschillend getal dat aan bovenstaande definitie voldoet.1 Daarom wordt het reële veld archimedisch genoemd (hoewel historisch gezien 'eudoxisch' beter zou zijn). In sectie 3.1 zullen we zien dat de hyperreële getallen ook een veld vormen, waar wel infinitesimalen en oneindig grote getallen in voorkomen. Een hyperreëel veld wordt dan ook niet-archimedisch genoemd.

\subsection{Zenonische magnitudeparadox}

Hoewel het geen synoniemen zijn, is de vroege geschiedenis van infinitesimalen nauw verstrengeld met die van ondeelbare atomen of indivisibilia. Dergelijke ondeelbare delen werden al besproken door de pre-socratische natuurfilosofen van Elea. De paradoxen van Zeno zijn nog steeds welbekend. Daarbij is de vraag niet alleen wiskundig, maar ook natuurkundig van aard: zijn de materie, de fysieke ruimte en de tijd werkelijk oneindig deelbaar, of stuit men uiteindelijk op ondeelbare atomen en discrete posities en momenten?

De vier bewegingsparadoxen van Zeno en zijn onvolledig overgeleverde paradoxen van meervoudigheid maken deel uit van één groot project: aantonen dat ontologisch pluralisme een inconsistente positie is (Owen, 1957-1958). Een theoretische reconstructie brengt een onderliggend argument aan het licht dat over magnitude gaat. Het doel van het argument is: aantonen dat de claim dat een lijnsegment opgebouwd is uit oneindig veel gelijke delen absurd is. Deze claim werd door Skyrms (1983: 235) uitgesplitst in premisses 1-3 hieronder.

Op basis van Skyrms (1983), kunnen we de zenonische magnitudeparadox als volgt formuleren:

Premisse 1 - Partitie of oneindige deelbaarheid: Een lijnsegment van positieve magnitude kan gepartitioneerd worden in een oneindig aantal delen.

Premisse 2 - Meetbaarheid: Dit kan gebeuren zodanig dat het concept magnitude van toepassing is op de delen.

Premisse 3 - Invariantie of uniformiteit: Dit kan gebeuren zodanig dat de delen elk dezelfde magnitude hebben (al dan niet nul).

Premisse 4 - Archimedisch axioma: Er bestaan geen infinitesimale magnitudes.

Premisse 5 - Perfecte additiviteit: De magnitude van een geheel is gelijk aan de som van de magnitudes van de delen.

Uit premisses 1-4 volgt een centraal dilemma: ofwel hebben de gelijke delen magnitude nul ofwel hebben ze een positieve, niet-infinitesimale magnitude. Beide opties leiden via premisse 5 echter tot een contradictie met de aanname dat het lijnsegment een eindige magnitude had:

- $\quad$ Als de delen magnitude nul hebben, dan heeft het lijnsegment magnitude nul.

- Als de delen positieve magnitude hebben, dan heeft het lijnsegment een oneindige magnitude.

Zeno's conclusie hieruit is dat de aanname - dat een lijnsegment opgebouwd is uit oneindig veel gelijke delen - absurd is. Dit past in zijn programma, dat erop gericht is aan te tonen dat het inconsistent is om ontologische veelheid te veronderstellen.

\footnotetext{
${ }^{1}$ Sommige auteurs noemen nul ook infinitesimaal, anderen niet. De hier gebruikte definitie laat dat in het midden. De kwestie is telkens of er van nul verschillende infinitesimalen zijn.
} 
Premisse 5, perfecte additiviteit, wordt ingeroepen in beide takken van dit centrale dilemma. Skyrms (1983) merkte op dat deze aannname aanvaard werd door alle partijen aan het debat: de school van Plato, die van Aristoteles en de atomisten. In de hedendaagse maattheorie echter wordt perfecte additiviteit afgezwakt naar aftelbare additiviteit. Dat lost het probleem op voor een continue, overaftelbare verzameling (Grünbaum, 1952), maar de eerlijke, aftelbaar oneindig loterij blijft een geval apart (zie ook sectie 3.5).

Merk verder op dat infinitesimalen bij voorbaat uitgesloten zijn van het argument (in premisse 4). Om de interne consistentie van dit concept na te gaan, volstaat dit argument dus niet.

\section{3 $\quad$ Aristoteles}

Vanwege de zenonische paradoxen werd de notie van indivisibilia in de oudheid al als problematisch aanzien. Aristoteles verwierp indivisibilia dan ook: in Boek VI van zijn Fysica staat dat een continuüm niet opgedeeld kan worden in delen die zelf geen onderdelen hebben. Dit had grote invloed, zeker op de middeleeuwse scholastici.

Infinitesimalen zijn echter niet onlosmakelijk met indivisibilia verbonden en kunnen de basis vormen van een alternatief aristotelisch continuüm (sectie 3.4).

\subsection{Archimedespalimpsest}

Ondanks hun problematische status bleken indivisibilia en infinitesimalen wel handige vuistregels op te leveren voor wiskundigen. In de derde eeuw v.Chr. toonde Archimedes hoe hij gebruik maakte van indivisibilia in zijn berekening van het volume van een bol. Hij deed dit in 'De methode van de mechanische stellingen', dat de vorm aanneemt van een brief aan Eratosthenes. Archimedes schreef zijn collega hoe hij nieuwe stellingen ontdekte, alvorens ze definitief te bewijzen. Dit werk werd lang verloren geacht, maar in de twintigste eeuw werd een palimpsest ontdekt: een tiende-eeuwse, Byzantijns-Griekse kopie van 'De methode', overschreven in de dertiende eeuw.

Indivisibilia zijn bijvoorbeeld alle parallelle vlakke doorsnedes die samen een ruimtelijk volume uitmaken. Deze ondeelbare snijvlakken dragen dan elk een infinitesimaal bij aan het volume. Toch neemt Archimedes expliciet als vijfde axioma aan dat alle grootheden eudoxisch zijn (archimedisch, dus): actuele infinitesimalen worden daarmee uitgesloten. Waar mogelijk probeerde hij bovendien, net als andere oud-Griekse wiskundigen, bewijzen die op de heuristische methode met indivisibilia steunden te vervangen door bewijzen op basis van de uitputtingsmethode van Eudoxus: daarbij wordt een oppervlak met gekromde omtrek benaderd door één of meerdere veelhoeken.

Eduard Jan Dijksterhuis (1934-1944, hoofdstuk X) vertaalde 'De methode' in het Nederlands. Hij duidde het belang van het terugvinden van deze bron als volgt:

De Methode heeft ons onthuld - en hierin ligt de eminente beteekenis van haar ontdekking - dat de indivisibilia slechts uit de gepubliceerde verhandelingen waren verbannen, maar dat zij in de werkplaats van den productieven wiskundige onverzwakt de scheppende kracht bleven uitoefenen, die zij in latere perioden - bij Cavalieri, bij Galilei, bij Huygens, bij Leibniz - nog zoo vaak zouden ontplooien. (Dijksterhuis, 19341944, hoofdstuk X: 16)

\subsection{Bloeitijd van infinitesimalen in de zeventiende eeuw}

De antieke bronnen raakten grotendeels vergeten in het Westen, maar bleven overgeleverd worden in de Arabische wereld. Vanaf de twaalfde eeuw werd het werk van Aristoteles herontdekt in Europa en vertaald in het Latijn. Thomas van Aquino integreerde aristotelische 
ideeën met de katholieke leer. In de zestiende eeuw werd er een Latijnse vertaling uitgegeven van het werk van Archimedes (weliswaar zonder 'De methode'). Dat luidde een heropleving in van de interesse in infinitesimalen onder Europese geleerden, aanvankelijk vooral in Italië. Deze periode is levendig beschreven door Alexander (2014), de belangrijkste bron voor deze sectie.

In de zeventiende eeuw maakte Galileo Galilei gebruik van infinitesimalen, net als zijn volgelingen - waaronder Bonaventura Cavalieri en Evangelista Torricelli. Terwijl Cavalieri erg bezorgd was over de paradoxen waarmee infinitesimalen al van in de oudheid omringd waren, zag Torricelli in deze paradoxen juist een aantrekkelijke uitdaging. Veel - maar zeker niet alle analytisch georiënteerde filosofen zullen deze aantrekkingskracht van paradoxen herkennen. Paradoxen zijn namelijk conceptuele gedachte-experimenten: ze bieden ons de kans om onze concepten onder druk te zetten en systematisch te onderzoeken welke al dan niet een consistent geheel vormen.

Wij kennen Torricelli hoofdzakelijk als uitvinder van de barometer; hij heeft dan ook nooit over infinitesimalen gepubliceerd. Galilei en Cavalieri hebben dat wel gedaan. Cavalieri werkte, in navolging van Archimedes, een eigen versie van de methode van de indivisibilia uit. Eeuwenlang zou zijn moeilijk te doorgronden hoofdwerk dé referentie blijven voor wiskundigen die infinitesimalen wilden gebruiken en het gebrek aan fundering ervan wilden verdoezelen.

Het gebruik van indivisibilia was de Jezuïeten een doorn in het oog: zij oordeelden dat het in tegenspraak was met de fysica van Aristoteles. In de wiskunde hielden zij de euclidische meetkunde als ideaal, waarin het postulaat van Eudoxus infinitesimalen uitsluit. Het onderwijzen van indivisibilia of infinitesimalen werd systematisch verboden. Dit had de grootste impact in Italië, waar de macht van de katholieke leiders het sterkste was.

Steunend op het werk van Diophantus (een hellenistische wiskundige uit de derde eeuw), introduceerde Pierre de Fermat het begrip van benaderende gelijkheid op een infinitesimaal na (dat hij adaequalitas noemde; zie bijvoorbeeld Katz, Schaps \& Shnider, 2013). Dit idee speelt nog steeds een belangrijke rol in de epsilon-delta-definitie van de limiet (zie sectie 2.6). De methode van Fermat kon gebruikt worden om raaklijnen aan krommen te bepalen. Descartes ontwikkelde in deze periode een andere methode met hetzelfde doel. Die 'normaalmethode' van Descartes had meer impact op zijn tijdgenoten, terwijl latere ontwikkelingen juist beter aansluiten bij het werk van Fermat (Katz, Schaps \& Shnider, 2013).

John Wallis populariseerde de lemniscaat, $\infty$, als symbool voor oneindig. Bovendien gebruikte

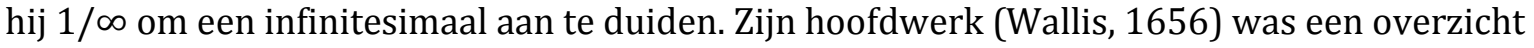
en verderzetting van het werk van Cavalieri en Descartes.

Aan het einde van de zeventiende eeuw kwamen zowel Newton als Leibniz tot een grote synthese: ze ontwikkelden de calculus of 'differentiaal- en integraalrekening' nagenoeg gelijktijdig (Hall, 1980). Daarbij steunden ze beiden op het werk van Fermat, Wallis en andere wiskundigen. Bij Newton is het centrale begrip het 'fluxion' - de afgeleide van een continue grootheid -, terwijl bij Leibniz infinitesimale differentialen en oneindige sommen een belangrijker heuristisch instrument waren. Hij introduceerde de notatie $\mathrm{d} x / \mathrm{d} t$ voor afgeleiden, wat bij hem letterlijk geïnterpreteerd mag worden als een breuk van twee infinitesimale grootheden (Bos, 1974). Bij Leibniz speelde de continuïteitswet een belangrijke rol, die zegt dat wat geldt voor eindige getallen ook moet gelden voor oneindige en vice versa. ${ }^{2}$ De transcendente

\footnotetext{
2 Dit kan natuurlijk niet waar zijn in volledige algemeenheid, maar in de jaren 1960 is Robinson (zie sectie 3.1) erin geslaagd om deze vuistregel heel precies te formuleren en zo exact af te bakenen welke eigenschappen wel en welke niet overgedragen kunnen worden tussen het eindige en oneindige domein.
} 
wet van de homogeniteit was een tweede heuristisch principe: dit liet Leibniz toe om aan het einde van een berekening enkel de laagst voorkomende macht van infinitesimalen te behouden. ${ }^{3}$

De zeventiende-eeuwse calculus kan met recht 'infinitesimaalrekening' genoemd worden. In het Frans was de term 'les infiniment petits' voor infinitesimalen gangbaar, bijvoorbeeld in de titel van het boek van Guillaume de l'Hôpital (1696).

In de zeventiende eeuw werd ook de basis gelegd voor een eerste wiskundige theorie voor waarschijnlijkheid. In de correspondentie tussen Pascal en Fermat over kansrekening (Devlin, 2010) kwam het hoogst onwaarschijnlijke niet aan bod, maar Pascal vond het wel nodig om infinitesimale waarschijnlijkheden uit te zonderen van zijn befaamde nutsargument voor het geloof. ${ }^{4}$ In de huidige standaard kansrekening is geen plaats meer voor infinitesimalen: hoe dat komt zien we in de volgende sectie.

\subsection{Kritiek op infinitesimalen na Leibniz en Newton}

Alexander (2014) eindigt zijn boek met de vaststelling dat Wallis gewonnen had. Hij stelt het voor alsof infinitesimalen - via calculus en analyse, over de mechanica en zowat alle takken van de fysica, naar de toepassingen ervan - de wereld voorgoed veranderden. Maar omdat zijn verhaal stopt met de dood van Wallis, vertelt hij er niet bij dat de weerstand tegen infinitesimalen groot is gebleven. Het woord bleef wel in gebruik, in het informele discours van natuurkundigen en ingenieurs, maar bij wiskundigen waren niet-archimedische grootheden grotendeels taboe tot in de jaren 1960. Laat me dus verdergaan waar Alexanders verhaal stopt: in de achttiende en negentiende eeuw verdwenen infinitesimalen uit de mainstream, maar een minderheid van wiskundigen bleef onderzoek verrichten naar niet-archimedische velden.

In de achttiende eeuw groeide de onrust over het gebruik van infinitesimalen, die weliswaar de motor vormden voor krachtige nieuwe resultaten, maar die zelf onvoldoende onderbouwd waren. Isaac Barrow en George Berkeley stonden vijandig ten aanzien van het gebruik van infinitesimalen in het werk van Leibniz en Newton. Berkeley betoogde (1734) dat de notie inconsistent was en vergeleek infinitesimalen met de 'geesten van overleden grootheden' - nu eens verschillend van nul, dan weer niet. ${ }^{5}$

Toch werden oneindig kleine grootheden nog systematisch gebruikt in het werk van Leonhard Euler, Joseph-Louis Lagrange en Augustin-Louis Cauchy. Cauchy gebruikte infinitesimalen bijvoorbeeld in zijn definitie voor continuïteit. Het werk van deze wiskundigen werd opgenomen in de mainstream en daarbij werden hun infinitesimalen geherinterpreteerd in termen van archimedische grootheden (zoals toegelicht in de laatste paragraaf van deze sectie).

Anders is het gesteld met Paul du Bois-Reymond: hij onderzocht expliciet alternatieve continua die echte infinitesimalen bevatten (Fisher, 1981). Hij keek daarbij naar de snelheid van convergentie of divergentie van functies. We vinden bij du Bois-Reymond (1882: 75)

\footnotetext{
${ }^{3}$ Ook dit is verwant aan een onderdeel uit Robinsons formalisme: een functie die het infinitesimale deel afrondt.

${ }^{4}$ Hij omschreef het als 'oneindige risico's op verlies tegen die van winnen'. De relevante zin uit fragment 397 (Pascal 1670; 1932; mijn cursivering) luidt: 'Cela ôte tout parti : partout où est l'infini, et où il n'y a pas infinité de hasards de perte contre celui du gain, il n'y a point à balancer, il faut tout donner.'

${ }^{5}$ Er kan door infinitesimalen gedeeld worden (zoals blijkt uit Leibniz' notatie voor afgeleide), maar aan het einde van de berekening worden infinitesimalen afgerond (Leibniz' transcendente wet van de homogeniteit).
} 
bijvoorbeeld een uitspraak die lijkt op de continuïteitswet van Leibniz: 'Das Unentlichkleine ist eine mathematische Grösse und hat mit dem Endlichen desen sämmtliche Eigenschaften gemein.' De wiskundige studie van systemen met infinitesimalen werd ook verdergezet door Tullio LeviCivita, Giuseppe Veronese en anderen aan het einde van de negentiende en begin de twintigste eeuw (Ehrlich, 2006).

Du Bois-Reymonds ideeën werden echter hevig bestreden, vooral door Georg Cantor (Fisher, 1981). Cantor ontwikkelde samen met Richard Dedekind een abstracte theorie van het archimedische continuüm van de reële getallen binnen de verzamelingentheorie (Ehrlich, 2006).

Samen met de epsilon-delta-definitie van de limiet werd daarmee ook de basis gelegd voor de hedendaagse analyse. Bernard Bolzano had in de negentiende eeuw al de eerste epsilon-deltadefinitie gegeven voor de limiet van een functie, op basis van het werk van Fermat en anderen, maar zonder gebruik van echte infinitesimalen. Het belang van Bolzano's limietbegrip werd pas ingezien door Karl Weierstrass, de vader van de moderne analyse. Op basis van dit limietbegrip zijn ook de afgeleide en integraal gedefinieerd. Hoewel epsilon en delta in de definitie van de limiet nog steeds 'infinitesimalen' genoemd worden, zijn het reële getallen uit een archimedisch veld en voldoen ze dus niet aan de definitie voor infinitesimaal uit sectie 2.1.

\subsection{Kanstheorie zonder infinitesimalen}

Aan het begin van de twintigste eeuw verklaarde Bertrand Russell de infinitesimaal uitgebannen uit de wiskunde (Ehrlich, 2006). De verzamelingentheorie, die het raamwerk vormt voor de analyse, werd op punt gesteld met de axiomatisatie van Zermelo-Fraenkel en het keuzeaxioma. Zo ontstond de huidige maat- en integratietheorie, die volledig gebaseerd is op een archimedisch begrip van het continuüm, voorgesteld door het veld van reële getallen. Het is op diezelfde basis dat onze waarschijnlijkheidsrekening werd geënt. Dit beantwoordt de vraag waarom er in de standaard kansrekening geen infinitesimalen voorkomen: dat begrip was de vorige eeuwen systematisch uit de onderliggende maattheorie geweerd, omdat wiskundigen vreesden dat het een intrinsiek incoherent begrip was.

Andrej Kolmogorov (1933) gaf een axiomatisatie voor het begrip waarschijnlijkheid en voorzag daarmee het zesde probleem van Hilbert (1900) van een oplossing. Vanaf dat moment kan men een kansfunctie zien als een genormeerde maat: een subklasse van functies uit de standaard maattheorie. Bovendien worden de axioma's van Kolmogorov aanvaard voor uiteenlopende filosofische interpretaties van het begrip waarschijnlijkheid, gaande van subjectieve maar rationele graden van overtuiging tot objectieve kansen van fysisch indeterministische processen.

Het enige axioma van Kolmogorov dat controversieel bleek in de personalistische interpretatie is het axioma van continuïteit. Dit axioma, dat rechtstreeks is ontleend aan de maattheorie, regelt de manier waarop omgegaan wordt met sommen bij oneindige uitkomstenruimtes. Binnen de context van Kolmogorovs andere axioma's is het equivalent aan het vereisen van aftelbare additiviteit. Eindige additiviteit vereist dat de kans van een unie van eindig veel disjuncte gebeurtenissen gelijk is aan de som van hun kansen; aftelbare additiviteit breidt die vereiste uit naar aftelbaar oneindig veel verzamelingen. De Finetti vond dit axioma onvoldoende gefundeerd voor rationele graden van overtuiging. Anderzijds kan je je afvragen waarom er geen overaftelbare additiviteit geëist wordt. In elk geval heeft dit axioma als gevolg dat de standaard kansrekening geen uniforme waarschijnlijkheidsverdeling over een aftelbare verzameling kan specifiëren - precies zoals het er stond in de voetnoot bij Norton (2013) waar ik over struikelde. 


\section{Infinitesimale waarschijnlijkheid}

Ongeveer op hetzelfde moment dat de waarschijnlijkheidsrekening haar huidige vorm kreeg, is er nog iets anders gebeurd, dat aanvankelijk weinig met maat- of kansrekening te maken had. Achteraf gezien was het toch een belangrijke eerste stap naar een alternatieve benadering ervan. Daarom volg ik in secties 3.1 en 3.2 de chronologie. Daarna licht ik in secties 3.3-3.6 vier thema's uit.

\subsection{Alternatieve analyse en maattheorie met infinitesimalen}

Thoralf Skolem (1934) bewees het bestaan van niet-standaard modellen van de rekenkunde van Peano. Deze methode uit de wiskundige logica kan ook toegepast worden op de eerste-orde axioma's van reële velden. Steunend op werk van Edwin Hewitt (1948) en Jerzy Łoś (1955), was Abraham Robinson (1961) de eerste die dergelijke niet-standaard modellen van reële gesloten velden onderzocht met het oog op een alternatieve formalisatie van de analyse, die dichter aanleunt bij de calculus van Leibniz. Zo voorzag Robinson de heuristische principes van Leibniz van een rigoureuze onderbouwing met behulp van infinitesimalen. ${ }^{6}$ Robinson (1966) noemde zijn theorie 'niet-standaard analyse' en de niet-standaard modellen van reële gesloten velden noemde hij 'hyperreële' velden: hiertoe behoren infinitesimale, eindige niet-infinitesimale en oneindige getallen.

Laat me hierbij schetsen hoe een hyperreëel veld geconstrueerd wordt. We vertrekken van de eigenschappen van de reële getallen in eerste-orde logica. Een model hiervoor bevat een oneindig alfabet met een naam voor elk reëel getal. Vervolgens maken we een ander model door een nieuw symbool in te voeren, $R$, waarvan we veronderstellen dat het groter is dan alle reële getallen in het oorspronkelijke model. Deze $R$ stelt een oneindig hyperreëel getal voor. Bovendien veronderstellen we ook in het uitgebreide model dat de eerste-orde eigenschappen van de reële getallen gelden: het moet gesloten zijn onder eerste-orde bewerkingen. Hierdoor zullen ook bijvoorbeeld $R+1$ en $R^{2}$ gedefinieerd zijn en corresponderen met andere oneindige getallen. Ook $1 / R$ is gedefinieerd en is een van nul verschillend infinitesimaal getal, evenals $1 /(R+1)$ en $1 / R^{2}$. Zo hebben we in één klap oneindig veel oneindig grote en oneindig kleine getallen in het niet-standaard model geïntroduceerd. Alle getallen in zo'n uitgebreid model samen vormen een hyperreële verzameling. Aangezien de reële getallen samen met de algebraïsche hoofdbewerkingen een geordend veld vormen, geldt dat ook voor de nietstandaard getallen. Dit noemen we een hyperreëel, geordend veld.

\subsection{Alternatieve kanstheorie met infinitesimalen}

Op basis van Robinsons niet-standaard analyse kunnen we een alternatieve waarschijnlijkheidsrekening opstellen, die recht doet aan mijn initiële intuïtie: in een eerlijke loterij op de natuurlijke getallen heeft elke specifieke uitkomst dezelfde, infinitesimale kans om uitgeloot te worden en de kansen van al die loten samen sommeren tot 1.

Hoewel alle technieken uitgedokterd waren, bestond er tot mijn verrassing geen nietarchimedische waarschijnlijkheidstheorie die dit specifieke probleem precies zo oplost. Er waren wel andere theorieën, maar geen die aan een standaard verzameling een hyperreële waarde toekent (zonder de infinitesimalen achteraf af te ronden).

\footnotetext{
${ }^{6}$ De continuiteitswet wordt geformaliseerd door het Transfer-principe en de transcendente wet van homogeniteit door een functie die het unieke standaard deel van een begrensd hyperreëel getal. (Zie ook voetnoten 2 en 3.)
} 
Samen met logicus Leon Horsten publiceerde ik dit resultaat voor de eerlijke loterij op de natuurlijke getallen (Wenmackers \& Horsten, 2013). Ik ontdekte dat onze aanpak nauw verwant was met een recente theorie over het oneindige van wiskundige Vieri Benci (zie sectie 3.6). Ik contacteerde hem en samen ontwikkelden we een axiomatisatie van een veel algemenere theorie, die zowel uniforme als niet-uniforme verdelingen en uitkomstenruimten van eender welke kardinaliteit kan beschrijven (Benci, Horsten \& Wenmackers, 2013).

Hoewel onze theorie bewezen consistent is, worden er nog steeds filosofische argumenten gepubliceerd tegen theorieën met infinitesimale waarschijnlijkheden. We hebben dergelijke bezwaren besproken en beantwoord in Benci, Horsten \& Wenmackers (2018).

Hier wil ik toch één bezwaar uitlichten, omdat ik vermoed dat het met name onder Nederlandse logici en wiskundigen leeft, vanwege de invloed van Brouwers intuïtionisme. De constructie van onze kansmaat vergt namelijk een (bijzonder type) van een vrije ultrafilter. Voor de definitie ervan verwijs ik naar de artikels - hier is vooral van belang dat dit een 'onaanraakbaar' object is: een object waarvan (onder bepaalde verzamelingtheoretische aannames) bewezen kan worden (i) dat het bestaat en (ii) dat er geen expliciet voorbeeld van gegeven kan worden. Voor aanhangers van het constructivisme is onze kanstheorie geen acceptabel alternatief, aangezien zij een expliciete constructie vereisen alvorens het bestaan van een wiskundig object te aanvaarden. Hierbij moet wel opgemerkt worden dat de standaard kanstheorie ook is ingebed in een verzamelingentheorie met een niet-constructief axioma (het keuzeaxioma). Om die reden vinden mijn co-auteurs en ik dit geen doorslaggevend argument tegen onze theorie.

\subsection{Kansrekening als motivatie voor niet-standaard analyse}

We hebben gezien dat vragen over de grondslagen van kansrekening de aanleiding kunnen vormen om op zoek te gaan naar een niet-archimedisch alternatief. Dat gebeurde toen ik Nortons voetnoot las, maar het was al meermaals eerder gebeurd.

Bij de Finetti (1936), bijvoorbeeld, al koos hij ervoor om het archimedische veld te behouden en enkel de aftelbare additiviteit te verwerpen. Het is echter duidelijk dat hij perfecte additiviteit verkoos, ware het niet dat hij meende dat dit onhaalbaar was. Het gebeurde ook bij Rudolf Carnap, op basis van het werk van Abner Shimony (1955). Shimony had namelijk geprobeerd om strikte coherentie op te leggen aan graden van overtuiging: daarbij mag waarschijnlijkheid nul enkel toegekend worden aan logisch onmogelijke proposities (of de lege verzameling), maar Shimony besefte dat de standaardkansrekening daar in het algemeen niet aan kan voldoen. $\mathrm{Om}$ die reden experimenteerde Carnap met niet-archimedische axioma's en dat kort voor Robinson (1961); doordat Carnaps werk pas postuum en post-Robinson gepubliceerd werd (in 1980), was de invloed ervan echter klein. (Zie Wenmackers, aanvaard voor een uitgebreider overzicht.)

We zien dus dat overwegingen die specifiek over kansrekening gaan gebruikt kunnen worden als motivatie voor niet-standaard analyse in het algemeen. Ook Skyrms (1983) verbond Zeno's magnitudeparadox (cf. sectie 2.2) met personalistische waarschijnlijkheid. Het is welbekend dat er in de standaard maattheorie onmeetbare verzamelingen bestaan. Welnu, schreef Skyrms (1983: 247), het is één ding om toe te geven dat er pathologische verzameling van punten zijn waaraan geen volume toegeschreven kan worden, maar iets helemaal anders om te zeggen dat er proposities zijn waaraan geen graad van overtuiging kan worden toegekend. Bovendien wordt de epistemologische vrijheid beknot doordat sommige kansverdelingen onmogelijk blijken.

Om die vrijheidsbeperking in het toekennen van graden van overtuiging te voorkomen kunnen we perfecte additiveit en uniformiteit behouden, en de premisse van meetbaarheid versterken. 
Dat leidt enkel tot een consistente theorie als we magnitudes uit niet-archimedische velden toelaten.

\subsection{Infinitesimale kansen versus indivisibilia}

Gezien de historische verwantschap tussen indivisibilia en infinitesimalen kunnen we ons afvragen of de infinitesimale kansen uit de nieuwe theorie ondeelbaar zijn. Het antwoord is negatief: de hyperreële getallen vormen een veld en daarin is elk getal deelbaar door alle andere getallen behalve nul. Het hyperreële veld is vrij van 'ondeelbare delen' en kan dus gezien worden als een alternatieve formalisering van het aristotelische continuïteitsbegrip.

Hoewel de infinitesimale waarschijnlijkheden uit onze theorie algebraïsch deelbaar zijn, corresponderen ze wel met atomen in de volgende zin: ze representeren de waarschijnlijkheid van elementaire mogelijke uitkomsten (in een verzameling waar er oneindig veel van dergelijke uitkomsten zijn), dus singletons uit de uitkomstenruimte. Het zijn de kleinste kansen die we - in een specifieke context - aan een mogelijke gebeurtenis toekennen.

Als we van uniformiteit afstappen, kunnen de 'atomaire', infinitesimale kansen bovendien onderling van elkaar verschillen. Hier zie ik een analogie met de betekenis van quantum in de quantummechanica. Hoewel bijvoorbeeld de energie gequantiseerd kan zijn, betekent dat niet dat het heelal is opgebouwd uit discrete en onderling gelijke energetische indivisibilia: de grootte van energiequanta hangt af van de omgeving (bijvoorbeeld, in een atoom) en de toegestane, discrete groottes kunnen tussen omgevingen op continue wijze van elkaar verschillen.

\subsection{Wat de eerlijke, aftelbaar oneindige loterij bijzonder maakt}

De magnitudeparadox van Zeno uit sectie 2.2 gaat over een continue grootheid, namelijk de lengte van een lijnstuk. Bij de loterij over de natuurlijk getallen gaat het over een discrete uitkomstenverzameling, maar premissen 1-3 van het zenonische argument lijken onverminderd van toepassing: de oneindige en gelijke delen in kwestie zijn de singletons van de verzameling, waaraan we elk dezelfde kans willen toekennen. Als we ook premissen 4 en 5 toevoegen, waarbij we bovendien vereisen dat de kans van de volledige uitkomstenverzameling 1 is (normering), komen we tot het centrale zenonische dilemma:

- Als we kans nul toekennen aan de elementaire uitkomsten, sommeren deze kansen tot nul, wat in tegenspraak is met de aannames.

- $\quad$ Als we een gelijke kans groter dan nul (en niet-infinitesimaal) toekennen aan de elementaire uitkomsten, dan divergeert de som, wat opnieuw in tegenspraak is met de aannames.

De maattheorie, die perfecte additiviteit verwerpt en enkel aftelbare additiviteit behoudt, blokkeert de continue versie van de paradox doordat een continuüm niet gevormd kan worden uit een aftelbare unie van singletons (Grünbaum, 1952). Bij een loterij op de natuurlijke getallen hebben we echter te maken met een aftelbare verzameling: dan kunnen we via een aftelbare unie vanuit singletons tot de volledige verzameling komen en wordt de additiviteit van kansen wel geacht om alle singleton-kansen tot één te laten sommeren. Maar dat kan niet, bij gelijke singleton-kansen, vanwege bovenstaand dilemma. Het paradoxale resultaat blijft dus staan. De conclusie die de standaard kansrekening hieruit trekt is dat er geen kansmaat is die een uniforme verdeling over een aftelbaar oneindige uitkomstenverzameling beschrijft. Maar dat is geen oplossing - dat is toegeven dat er een probleem is! 
Het probleem is dat er geen aftelbaar oneindige deelverzameling van het archimedische eenheidsinterval bestaat die zowel discreet als uniform verdeeld is, zoals bewezen door Tatyana van Aardenne-Ehrenfest (1945; 1949).

Er zijn twee voor de hand liggende oplossingen: niet normeren en oneindig grote 'kansen' introduceren, of infinitesimale kansen toelaten. Beide oplossingen vereisen een nietarchimedisch veld en beide steunen hevig op de intuïtie van perfecte additiviteit. (Als je die intuïtie niet deelt, of kost wat kost niet-archimedische kansen wil vermijden, dan is er nog een derde oplossing: de Finetti's keuze om de additiviteitsvereiste te beperken tot eindige unies en sommen.)

Als we ons tijdelijk geen zorgen maken over normering, dan komt de vraag over een eerlijke loterij op de natuurlijke getallen in essentie neer op het 'tellen' en vergelijken van deelverzamelingen van natuurlijke getallen. De numerositeitstheorie van Benci doet precies dat. Numerositeit is een nieuwe maat voor de grootte van verzamelingen die voor eindige verzamelingen overeenkomt met de kardinaliteit, maar die voor oneindige verzamelingen fijnmaziger is dan kardinaliteit. Twee verzamelingen kunnen dus dezelfde oneindige kardinaliteit hebben terwijl ze een verschillende numerositeit hebben. Beschouw bijvoorbeeld de volgende vier verzamelingen: alle natuurlijke getallen, alle natuurlijke getallen zonder het element 1 , alle even natuurlijke getallen en alle perfecte kwadraten. Deze verzamelingen hebben allemaal dezelfde kardinaliteit (aftelbaar oneindig), maar ze hebben telkens een kleinere numerositeit. Het omgekeerde - verschillende kardinaliteit bij dezelfde numerositeit kan niet. Raadpleeg het artikel van Mancosu (2009) voor een uitstekende inleiding op de theorie.

Numerositeiten zijn in feite hypernatuurlijke getallen: dit houdt in dat alle algebraïsche operaties die gedefinieerd zijn op de natuurlijke getallen ook hierop gedefinieerd kunnen worden. Vanwege de rijke algebra die mogelijk is met numerositeiten, kan je een eerlijke loterij op een oneindig domein eenvoudig beschrijven via genormaliseerde numerositeiten, die een niet-archimedische kansmaat opleveren. Het hyperreële eenheidsinterval is continu, zoals besproken in sectie 3.4, maar bij onze oplossing gebruiken we er slechts een discrete, uniform verdeelde deelverzameling van.

Hoewel deze hyperreële maten gemotiveerd zijn vanuit overwegingen over één specifiek kansprobleem kunnen ze sterk veralgemeend worden. Zowel de theorie van numerositeiten als de verwante niet-archimedische waarschijnlijkheidstheorie kan veralgemeend worden naar domeinen van eender welke kardinaliteit. En deze technieken en resultaten kunnen ook weer toegepast worden op maattheorie in het algemeen.

\subsection{Waar stop je met het oneindige te tellen?}

We zagen in het historische overzicht dat infinitesimalen lang in het wiskundige verdomhoekje zaten. In dit licht is het instructief om het werk van Grünbaum (1952), geschreven vóór Robinson (1966), te vergelijken met het post-Robinsoniaanse werk van Skyrms (1983). Grünbaum (1952: 298) maakte er bijvoorbeeld een punt van om ons te wijzen op een denkfout aangaande infinitesimalen, gemaakt door Johan Bernoulli en na hem nog vele anderen, terwijl Skyrms (1983) de optie van niet-archimedische magnitudes duidelijk wel als een valabele uitweg zag voor het argument van Zeno.

Toch is het nuttig om iets langer stil te staan bij de denkfout die Grünbaum (1952) toeschreef aan Bernoulli en latere auteurs: ze doen alsof er een laatste stap is in de procedure van het oneindig opdelen van een lijnstuk in de dichotomieparadox. (Dat het lijnstuk daarbij in ongelijke delen wordt opgedeeld is voor het punt dat ik wil bespreken niet cruciaal.) Het idee van een 
'oneindigste' stap sluit nauw aan bij de etymologie van infinitesimaal en is dus verleidelijk. Als we het oneindig opdelen echter modelleren met de natuurlijke getallen, dan komen we in conflict met het feit dat die verzameling geen grootste element bevat. Er lijkt dus ook geen laatste element of stap te zijn.

Een vraag is of de aanname van een laatste element noodzakelijk is. Het antwoord blijkt 'nee' te zijn: numerositeitstheorie kent aan de verzameling van natuurlijke getallen een nietarchimedische grootte toe, zonder aan te nemen dat er een laatste element zou zijn.

Anderzijds kunnen we ook proberen om het idee van Bernoulli ernstig te nemen door één stap terug te zetten. Waarom zou je überhaupt een loterij op de natuurlijke getallen willen beschrijven? Wellicht was het oorspronkelijke doel iets te beschrijven dat analoog is aan eindige loterijen, maar dan níet eindig. Als je de analogie zo sterk mogelijk wil houden, dan moet de oneindige verzameling een discreet interval zijn met zowel een eerste als een laatste element. Daartoe kan je een interval van hypernatuurlijke getallen gebruiken (elementen uit een nietstandaard model van de rekenkunde, cf. sectie 3.1).

Eens je de keuze gemaakt hebt om met dergelijke 'hypereindige' intervallen te werken is verder werkelijk alles analoog aan een eindige loterij. Neem bijvoorbeeld het interval $\{1, \ldots, N\}$ uit de hypernatuurlijke getallen. Dan is de kans van elk singleton uit het interval bijvoorbeeld $1 / N$, wat een infinitesimaal is als $N$ een oneindig getal is. Dit illustreert de essentie van de radicaal elementaire kanstheorie van Edward Nelson (1987).

\section{Slotbeschouwingen}

Terwijl inzichten over het oneindig grote centraal staan in meerdere takken van de wiskunde, zijn infinitesimalen lange tijd met grote argwaan bekeken. Er zijn inmiddels echter meerdere theorieën waarin niet-archimedische grootheden op een consistente manier geformaliseerd kunnen worden: naast de al genoemde hyperreële getallen van Robinson zijn er ook de surreële getallen van Conway. Beide systemen zijn geschikt om infinitesimale kansen voor te stellen. (Daarnaast bestaan er nog andere theorieën over infinitesimalen, zoals smooth analysis, maar die laat ik hier geheel buiten beschouwing.)

Zullen infinitesimalen een voetnoot blijven in de wiskunde, of kunnen ze volledig gerehabiliteerd worden? Ik vermoed dat het antwoord ergens tussen beide extremen te vinden is. Er is hoop op een gedeeltelijke heropleving van de studie van infinitesimalen om verschillende redenen.

Bos (1974: 82-83) merkte op dat Robinsons latere theorie niet nodig is (of zou mogen zijn) om de infinitesimaalrekening van Leibniz te rehabiliteren. Dit lijkt me terecht: het is duidelijk dat Leibniz noch reële velden noch hyperreële velden gebruikte; zijn werk zou beoordeeld moeten worden met de kennis en normen van zijn eigen tijd als enige maatstaf. Toch valt het op dat de interesse en positieve waardering voor diverse oude infinitesimaaltheorieën toegenomen is sinds de jaren 1960. (In sectie 3.6 zagen we bijvoorbeeld het verschil in oordeel tussen Grünbaum, 1952 en Skyrms, 1983.) Het is nu eenmaal gemakkelijker om de waarde van ruwe ideeën te erkennen als je weet dat er een consistente reconstructie van te maken valt. Bovendien behoren de oude bronnen tot het publieke domein en hebben we er eenvoudige, digitale toegang toe - van het Archimedespalimsest over Leibniz tot du Bois-Reymond.7

\footnotetext{
${ }^{7}$ Voor wie zich verder wenst te verdiepen in dit onderzoek is het begin van een nieuw project dus slechts enkele klikken verwijderd. Vergeet dan achteraf niet erbij te vertellen dat het allemaal begonnen is met een voetnoot.
} 
Ondertussen is de status van axioma's sterk geëvolueerd is: waar axioma's in de oud-Griekse wiskunde en nog lang daarna de status hadden van onbetwijfelbare zekerheden, is de courante houding nu dat we verschillende axiomastelsels naast elkaar kunnen bestuderen en onderling vergelijken. Dat pluralistische standpunt laat ons toe om te wisselen tussen theorieën met en zonder infinitesimalen, hetzij omdat het probleem in kwestie zich beter leent voor de ene of de andere aanpak, hetzij omdat we de kracht van de theorieën zelf willen vergelijken. Als we een axiomastelsel overladen, kan het gebeuren dat er ongemerkt intern strijdige aannames gemaakt worden. Paradoxen signaleren dat dit gebeurd is en kunnen ons helpen een diagnose te stellen. Met zijn appreciatie voor paradoxen was Torricelli (cf. sectie 2.5) zijn tijd dus vooruit. Ook Paul du Bois-Reymond was uit op een neutrale vergelijking van methodes (1877: 151): 'Uebrigens ist es nicht unmöglich, dass gerade durch tiefere Untersuchung der Grundlagen des Infinitärcalcüls diejenigen der gewöhnlichen Analysis mehr Licht empfangen werden.'

Dit roept de vraag op of infinitesimalen zich bij uitstek lenen tot methodologisch pluralisme, of dat deze associatie enkel is ontstaan doordat het steeds een minderheidspositie was. Hierop moet ik het antwoord schuldig blijven.

Het meta-theoretische perspectief heeft mij alleszins geholpen om in te zien waarom een eerlijke loterij op de natuurlijke getallen niet beschreven kan worden met aftelbaar sommeerbare kansfuncties. Bovendien kan ik de Finetti's pleidooi om het te houden op eindige optelbaarheid, wat ik aanvankelijk een zwaktebod vond, nu begrijpen als het gevolg van het afronden van infinitesimale kansen. Enkel als de infinitesimalen niet worden afgerond, is de kansmaat perfect optelbaar. Mijn slogan, waarvan de clou zich helaas niet laat vertalen naar het Nederlands, is dan ook: without infinitesimals, probabilities just don't add up.

Mijn zoektocht die begon bij een voetnoot is hiermee afgerond - de weg uit dit vliegenglas gevonden. In mijn verdere onderzoek probeer ik kansmaten met infinitesimalen toe te passen op problemen uit het grondslagenonderzoek in de fysica, waaronder het maatprobleem in de kosmologie en vragen over indeterminisme in de klassieke fysica. Dat laatste was trouwens ook het onderwerp van het artikel van Norton waar dit hele project ooit mee begon.

\section{Dankbetuiging}

Met dank aan twee anonieme beoordelaars voor hun rapporten. Dit werk werd financieel ondersteund door FWO Vlaanderen via projecten G0B8616N en G066918N.

\section{Over de auteur}

Sylvia Wenmackers studeerde theoretische natuurkunde (UGent, 2002), behaalde een doctoraat in de experimentele natuurkunde (UHasselt, 2008) en verdedigde een proefschrift in de theoretische filosofie (cum laude, RUGroningen, 2011). Sinds 2014 is ze aangesteld als onderzoeksprofessor aan het Centrum voor Logica en Filosofie van de Wetenschappen van het Hoger Instituut voor Wijsbegeerte aan de KU Leuven. Ze is gespecialiseerd in grondslagen van de kansrekening en filosofie van de fysica. Daarnaast schrijft ze een maandelijkse column voor wetenschapsmagazine Eos en is ze lid van de Jonge Academie. 


\section{Bibliografie}

Alexander, A. (2014) Infinitesimal: How a dangerous mathematical theory shaped the modern world. London: Oneworld.

Benci, V., L. Horsten, S. Wenmackers (2013) Non-Archimedean probability, Milan Journal of Mathematics 81, pp. 121-151.

Benci, V., L. Horsten, S. Wenmackers (2018) Infinitesimal probabilities, The British Journal for Philosophy of Science 69, pp. 509-552.

Berkeley, G. (1734) The Analyst; a Discourse Addressed to an Infidel Mathematician. London: Strand.

Bos, H.J.M. (1974) Differentials, higher-order differentials and the derivative in the Leibnizian calculus, Archive for History of Exact Sciences 14, pp. 1-90.

Carnap, R. (1980) The problem of a more general concept of regularity, in: R.C. Jeffrey (red.) Studies in Inductive Logic and Probability, Vol. 2. University of California Press, pp. 145-155.

de Finetti, B. (1972) Probability, Induction and Statistics; The Art of Guessing. Wiley.

de l'Hôpital, G. (1696) Analyse des Infiniment Petits pour l'Intelligence des Lignes Courbes. Paris : Imprimerie Royal. Gedigitaliseerd door Linda Hall Library of Science, Engineering \& Technology; URL: http://lhldigital.lindahall.org/cdm/ref/collection/math/id/21037.

Devlin, K. (2010) The unfinished game: Pascal, Fermat, and the seventeenth-century letter that made the world modern. New York: Basic Books.

Dijksterhuis, E.J. (1934-1944) Archimedes, Euclides 11-20; Hoofdstuk X correspondeert met Euclides 17 (1940-1941). Gedigitaliseerd door Luuk Hoevenaars; URL https://goo.gl/dzwo2K.

du Bois-Reymond, P. (1877) Ueber die Paradoxen des Infinitärcalcüls, Mathematische Annalen 11, pp. 149-167.

du Bois-Reymond, P. (1882) Die allgemeine Functionentheorie. Tübingen: H. Laupp. URL: http://dx.doi.org/10.14463/GBV:895066262.

Ehrlich, P. (2006) The rise of non-Archimedean mathematics and the roots of a misconception I: The emergence of non-Archimedean systems of magnitudes, Archive for History of Exact Sciences 60, pp. 1-121.

Fisher, G. (1981) The infinite and infinitesimal quantities of du Bois-Reymond and their reception, Archive for History of Exact Sciences 24, pp. 101-163.

Grünbaum, A. (1952) A consistent conception of the extended linear continuum as an aggregate of unextended elements, Philosophy of Science 19, pp. 288-306.

Hall, A.R. (1980) Philosophers at War: The Quarrel between Newton and Gottfried Leibniz. Cambridge: Cambridge University Press.

Hewitt, E. (1948) Rings of real-valued continuous functions I, Transactions of the American Mathematical Society 64, pp. 54-99.

Hilbert, D. (1900) Mathematische Probleme, Göttinger Nachrichten, pp. 253-297.

Katz, M.G., D.M. Schaps, S. Shnider (2013) Almost equal: The method of adequality from Diophantus to Fermat and beyond, Perspectives on Science 21, pp. 283-324. 
Łoś, J. (1955) Quelques remarques, théorèmes, et problèmes sur les classes définissables d'algèbres. In: Mathematical Interpretation of Formal Systems (Symposium, Amsterdam 1954), Vol. 98 of Studies in Logic and the Foundations of Mathematics. Amsterdam: North-Holland, pp. $1-13$.

Mancosu, P. (2009) Measuring the size of infinite collections of natural numbers: Was Cantor's theory of infinite number inevitable? The Review of Symbolic Logic 2, pp. 612-646.

Nelson, E. (1987) Radically elementary probability theory. Annals of Mathematical Studies Vol. 117, Princeton: Princeton University Press.

Norton, J.D. (2003) Causation as folk science, Philosophers' Imprint 3, pp. 1-22.

Owen, G.E.L. (1957-1958) Zeno and the mathematicians, Proceedings of the Aristotelian Society 58, pp. 199-222.

Pascal, B. (1670; 1932) Pensées, editie van M. Le Guern; heruitgave (2004) Folio classique Vol. 4054, Paris: Gallimard.

Shimony, A. (1955) Coherence and the axioms of confirmation, The Journal of Symbolic Logic 20, pp. 1-28.

Skolem, Th. (1934) Über die Nicht-charakterisierbarkeit der Zahlenreihe mittels endlich oder abzählbar unendlich vieler Aussagen mit ausschliesslich Zahlenvariablen, Fundamenta Mathematicae 23, pp. 150-161.

Skyrms, B. (1983) Zeno's paradox of measure, in: R.S. Cohen en L. Laudan (red.) Physics, philosophy and psychoanalysis. Springer, Dordrecht, pp. 223-254.

Robinson, A. (1961) Non-standard analysis, Proceedings of the Royal Academy of Sciences, Amsterdam, ser. A, 64, pp. 432-440.

Robinson, A. (1966) Non-Standard Analysis. Amsterdam: North-Holland.

van Aardenne-Ehrenfest, T. (1945) Proof of the impossibility of a just distribution of an infinite sequence of points over an interval, Proceedings of the Koninklijke Nederlandse Akademie Van Wetenschappen 48, pp. 266-271.

van Aardenne-Ehrenfest, T. (1949) On the impossibility of a just distribution, Proceedings of the Koninklijke Nederlandse Akademie Van Wetenschappen 52, pp. 734-739.

Wallis, J. (1656) Arithmetica Infinitorum. Engelse vertaling: J.A. Stedall (2004) The Arithmetic of Infinitesimals. New York: Springer.

Wenmackers, S. (2011) Philosophy of Probability: Foundations, Epistemology, and Computation. Proefschrift, Rijksuniversiteit Groningen. URL: http://hdl.handle.net/11370/144e89d0-0229495d-8f05-89aa20c79b4b.

Wenmackers, S., en L. Horsten (2013) Fair infinite lotteries, Synthese 190, pp. 37-61.

Wenmackers, S. (aanvaard) Infinitesimal probability - an opinionated introduction, in: R. Pettigrew en J. Weisberg (red.), Open Handbook of Formal Epistemology. 